Sari Pediatri, Vol. 7, No. 3, Desember 2005: 153 - 159

\title{
Penanganan Nyeri pada Keganasan
}

\author{
Damayani Farastuti, Endang Windiastuti
}

Kasus seorang anak dengan retinoblastoma residif mata kiri stadium IV yang tidak responsif dengan sitostatika. Dalam perjalanan penyakitnya, masa tumor makin membesar dan menimbulkan keluhan nyeri. Nyeri pada pasien ini dapat disebabkan oleh aktivitas nosiseptor akibat regangan dan destruksi tulang, dan nyeri neuropatik akibat penekanan pada saraf di sekitar tumor. Penanganan nyeri dimulai dengan pemberian preparat AINS (anti inflamasi non steroid) yaitu natrium diklofenak dan parasetamol namun tidak dapat mengatasi keluhan pasien. Pasien kemudian diberikan tramadol supositoria dan natrium diklofenak gel.

Masa tumor yang terus membesar membuat frekuensi dan intensitas nyeri yang dirasakan bertambah hebat, dan tidak dapat lagi diatasi dengan terapi AINS. Pasien mengalami gangguan tidur, nafsu makan, dan juga menjadi sangat rewel. Berdasarkan rekomendasi WHO, maka terapi yang harus diberikan selanjutnya adalah golongan opioid kuat. Pasien diberi morfin oral $2 \mathrm{mg}, 3 \mathrm{kali}$ sehari, tramadol supositoria, dan natrium diklofenakgel. Keluhan nyeri teratasi dengan obat-obat tersebut. Tiga minggu kemudian, pasien kembali mengalami nyeri hebat. Hal ini disebabkan karena ibu tidak memberikan obat sesuai dengan jadwal yang dianjurkan, dengan alasan takut terjadi ketergantungan pada morfin. Dalam hal ini, peran dokter untuk memberikan informasi sejelas-jelasnya sangat penting, mencakup alasan pemberian morfin, dosis, efek samping, dan kemungkinan toleransi.

Kata kunci: nyeri, kanker, analgesik, anti inflamasi, opioid, paliatif

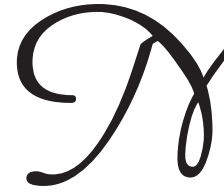
eri merupakan salah satu keluhan yang sering dijumpai pada pasien dengan keganasan. ${ }^{1}$ Masa tumor yang bertambah besar akan menekan saraf, tulang, dan organ lain yang ada di sekitarnya sehingga menimbulkan nyeri. Nyeri dapat juga disebabkan oleh adanya metastasis, prosedur tindakan diagnostik dan komplikasi terapi.

\footnotetext{
Alamat korespondensi:

Dr Endang Windiastuti, Sp.A(K)

Divisi Hematologi-Onkologi. Departemen Ilmu Kesehatan Anak FKUI-

RSCM. Jl. Salemba no. 6, Jakarta 10430.

Telepon: 021-31901170, 31901170 Fax.021-3913982.
}

Dr. Damayani Farastuti. PPDS Ilmu Kesehatan Anak FKUI.
Tata laksana nyeri merupakan salah satu bagian dari terapi paliatif. Terapi paliatif adalah terapi yang bertujuan untuk menghilangkan gejala atau keluhan, baik yang disebabkan oleh penyakit itu sendiri maupun sebagai komplikasi dari terapi kuratif, agar pasien mendapatkan kualitas hidup yang terbaik menjelang hari-hari terakhirnya. Seringkali dokter terlalu menitikberatkan pada terapi kuratif sehingga melupakan aspek paliatif dalam tata laksana keganasan pada anak. Terapi paliatif seharusnya mulai dipertimbangkan pada saat terapi kuratif tidak memberikan perbaikan. ${ }^{2}$

Tata laksana nyeri mencakup terapi farmakologis dan non farmakologis. World Health Organization (WHO) telah memberikan pedoman terapi farmakologis untuk nyeri yang digambarkan sebagai 
stepladder (anak tangga). Pada nyeri ringan, digunakan obat anti inflamasi non steroid (AINS) dan parasetamol. Jika nyeri tidak teratasi, maka dapat diberikan opioid lemah, seperti tramadol dan AINS. Jika nyeri tetap tidak teratasi, maka perlu dipertimbangkan pemberian opiod seperti morfin. ${ }^{3-5}$

\section{Kasus}

Seorang anak perempuan berusia 4 tahun di rawat di Departemen Ilmu Kesehatan Anak RS Dr. Cipto Mangunkusumo (IKA RSCM) Jakarta dengan diagnosis retinoblastoma mata kiri stadium IV residif. Satu tahun sebelumnya, pasien sudah didiagnosis retinoblastoma stadium II dan telah dilakukan operasi eksenterasi. Pasien kemudian mendapatkan kemoterapi dan hanya menyelesaikan tiga siklus kemoterapi.

Pasien kembali datang tujuh bulan kemudian dengan keluhan adanya benjolan baru pada bekas eksenterasi sejak empat bulan sebelumnya. Pada awalnya tumor sebesar kelereng di pelipis kiri, namun bertambah besar dan menjalar hingga ke dagu, konsistensi kenyal, berbenjol-benjol, dan tidak nyeri. Computed tomography scan menunjukkan adanya masa tumor luas di daerah periorbital, bukal, frontotemporal dan retromandibular kiri disertai destruksi tulang dinding orbita kiri.

Pada pemeriksaan fisis, ditemukan pasien sadar, tanda vital dalam batas normal. Berat badan $16 \mathrm{~kg}$, tinggi badan $99 \mathrm{~cm}$, dan lingkar lengan atas $12,5 \mathrm{~cm}$. Status gizi kurang, pada mata kiri terdapat masa berukuran $10 \times 10 \times 8 \mathrm{~cm}$ yang berhubungan dengan masa di pipi berukuran $6 \times 5 \times 3 \mathrm{~cm}$, konsistensi kenyal, berbenjol-benjol, tampak mengkilat dengan gambaran venektasi dan hiperemis tanpa disertai rasa nyeri. Mata kanan tidak ada kelainan, hidung bagian kiri tampak terangkat akibat desakan masa tumor. Pada leher tidak ditemukan pembesaran kelenjar getah bening. Jantung dan paru dalam batas normal. Perut lemas, turgor cukup, tidak terdapat pembesaran hati atau limpa, dan bising usus positif normal. Ekstremitas, akral hangat dan perfusi perifer baik. Direncanakan pemberian sitostatika yang terdiri dari ifosfamid $1500 \mathrm{mg} / \mathrm{m}^{2}$; vinkristin $1,5 \mathrm{mg} / \mathrm{m}^{2}$; dan aktinomisin D $1500 \mathrm{ug} / \mathrm{m}^{2}$

Setelah pemberian sitostatika, masa tumor tidak mengecil dan pasien mulai mengeluh nyeri. Pasien dikonsulkan ke Departemen Rehabilitasi Medik dan diberikan terapi natrium diklofenak $15 \mathrm{mg}$ jika nyeri, parasetamol, dan mylanta ${ }^{\circledR}$ untuk mengantisipasi efek samping gangguan saluran cerna. Obat diklofenak hanya diminum 1 kali dan tidak dilanjutkan karena pasien muntah.

Nyeri makin hebat, terutama pada malam hari dan menjalar sampai ke bahu sehingga membuat tangan kiri sulit digerakkan. Pasien menjadi sangat rewel dan tidak ada nafsu makan, kemudian diberikan tramadol supositoria jika sakit yang dirasakan cukup hebat dan natrium diklofenak gel. Setelah pemberian obat-obatan tersebut keluhan nyeri mulai berkurang.

Pasien kembali dirawat untuk pemberian sitostatika namun masa tumor terlihat makin membesar, meluas sampai ke mandibula kanan dengan konsistensi kenyal, dan terlihat gambaran venektasi. Keluhan nyeri yang dirasakan semakin sering muncul, terutama malam hari, sehingga pasien sukar tidur. Pasien mengalami nyeri kanker persisten sehingga diputuskan untuk diberikan terapi paliatif peroral dengan morfin $3 \times 2 \mathrm{mg}$ oral, tramadol supositoria pada malam hari jika terjadi nyeri dan diklofenak gel. Pasien juga disarankan untuk melakukan proper positioning untuk mengurangi tightness pada otot leher bagian belakang.

Keluhan nyeri teratasi dengan obat-obat tersebut dan awitan nyeri berkurang maka diputuskan dosis morfin tidak diturunkan secara bertahap karena dipikirkan kemungkinan nyeri akan bertambah berat akibat masa tumor yang makin membesar. Jika awitan nyeri semakin sering muncul, direncanakan untuk meningkatkan dosis morfin.

\section{Definisi Nyeri}

The International Study of Pain mendefinisikan nyeri sebagai perasaan sensorik dan emosional tidak menyenangkan yang dihubungkan dengan kerusakan jaringan yang telah atau akan terjadi atau digambarkan seperti mengalami kerusakan jaringan. ${ }^{3,6,7}$ Nyeri bersifat subyektif karena ambang nyeri setiap individu berbeda-beda. ${ }^{7}$ Ambang nyeri akan turun pada saat kita merasa lelah, cemas, sedih, marah, depresi, bosan, takut, dan terisolasi. Keadaan tidur, istirahat, rasa empati, diversi, dan pengertian akan meningkatkan ambang nyeri. ${ }^{3,7}$ 


\section{Insidens}

Insidens nyeri kanker pada anak berkisar antara 25$50 \%$. Lebih dari separuhnya disebabkan oleh terapi dan hanya seperempatnya yang disebabkan oleh kanker itu sendiri. ${ }^{5}$ Wolfe dkk. ${ }^{8}$ dalam penelitian yang dilakukan di Boston pada tahun 1997-1998, menyatakan bahwa $89 \%$ anak dengan keganasan mengalami penderitaan hebat pada hari-hari terakhir hidupnya, dan penderitaan yang sering dialami adalah rasa nyeri (27\%), pegal, atau sesak napas (16\%). Di Indonesia, Kusumawardani ${ }^{9}$ dalam penelitiannya mendapatkan 44 dari 128 (34.4\%) pasien anak di bangsal hematologi onkologi RSUD Dr. Soetomo Surabaya mendapat terapi paliatif dengan menggunakan analgesik.

\section{Patofisiologi}

Patofisiologi nyeri diawali dengan pengeluaran mediator-mediator inflamasi, seperti bradikinin, prostaglandin (PGE2 dan PGEa), histamin, serotonin, dan substansi $\mathrm{P}$ yang akan merangsang ujung-ujung saraf bebas. Stimulus ini akan diubah menjadi impuls listrik yang dihantarkan melalui saraf menuju ke sistem saraf pusat. Adanya impuls nyeri akan menyebabkan keluarnya endorfin yang akan berikatan dengan reseptor $\mathrm{m}, \mathrm{d}$, dan $\mathrm{k}$ di sistem saraf pusat. Terikatnya endorfin pada reseptor tersebut akan menyebabkan hambatan pengeluaran mediator di perifer, sehingga akan menghambat penghantaran impuls nyeri ke otak. ${ }^{6,10}$

Pada keganasan, nyeri yang disebabkan oleh aktivasi nosiseptor disebut nyeri nosiseptif; sedangkan nyeri yang ditimbulkan oleh gangguan pada sistem saraf disebut nyeri neuropatik. ${ }^{10}$ Nyeri nosiseptif terjadi akibat kerusakan jaringan yang potensial yang dapat disebabkan oleh penekanan langsung tumor, trauma, inflamasi, atau infiltrasi ke jaringan yang sehat dan dapat berupa nyeri somatik maupun viseral. Nyeri somatik terjadi akibat terkenanya struktur tulang dan otot, bersifat tajam, berdenyut, serta terlokalisasi dengan jelas. Nyeri viseral adalah nyeri nosiseptif yang disebabkan oleh penarikan, distensi, atau inflamasi pada organ dalam toraks dan abdomen. Nyeri viseral bersifat difus, tidak teralokalisasi, dan dideskripsikan sebagai tegang atau kejang disertai rasa mual dan muntah. $^{10,11}$
Nyeri neuropatik sering dijumpai pada pasien keganasan dan umumnya sulit untuk ditangani. ${ }^{12}$ Nyeri neuropatik dapat terjadi akibat kompresi saraf oleh masa tumor, trauma saraf pada prosedur diagnostik atau pembedahan, serta cedera sistem saraf akibat efek samping kemoterapi atau radioterapi. ${ }^{12}$ Adanya gangguan pada sistem saraf akan menyebabkan lepasnya muatan spontan dan paroksismal pada sistem saraf perifer dan pusat atau menyebabkan hilangnya modulasi inhibitor pusat. ${ }^{10}$ Karakteristik nyeri neuropatik adalah hiperalgesia (respon berlebihan terhadap stimulus yang menimbulkan nyeri) dan alodinia (nyeri yang disebabkan oleh stimulus yang secara normal tidak menyebabkan nyeri) ${ }^{11,13}$

\section{Diagnosis Nyeri}

Penegakan diagnosis nyeri pada anak seringkali sulit dilakukan karena sebagian besar anak tidak dapat mengatakan rasa nyeri yang dideritanya. Selain itu ada anggapan bahwa anak kurang dari 1 tahun kurang dapat merasakan nyeri karena mielinisasi susunan sarafnya belum sempurna, sehingga transmisi stimulus ke sistem saraf pusat terhambat. Hal tersebut dibantah oleh berbagai penelitian, seperti yang dikutip oleh Lazuardi ${ }^{14}$, yang menyatakan,

- Usia 20 minggu, korteks janin sudah dipenuhi oleh neuron sehingga ia dapat merasakan sakit. Saat lahir, ujung saraf nosiseptifnya sudah menyerupai orang dewasa.

- Belum sempurnanya mielinisasi tidak menghalangi anak untuk merasakan nyeri karena pada orang dewasapun impuls nosiseptif disalurkan melalui serabut yang tidak bermielin.

- Bayi prematur dan bayi dengan berat lahir rendah lebih sensitif terhadap nyeri dibandingkan dengan neonatus cukup bulan karena mekanisme inhibisi dari pusat belum berkembang dengan sempurna.

- Anak tidak dapat mengungkapkan rasa nyeri secara verbal, namun ada indikator fisiologis berupa peningkatan denyut jantung, penurunan saturasi oksigen, dan perubahan aktivitas fasial yang berkaitan dengan nyeri.

- Bayi yang lama dirawat di rumah sakit dan mengalami berbagai prosedur yang menimbulkan nyeri, akan memperlihatkan gejala menarik diri, kesulitan berkomunikasi, setelah keluar dari rumah sakit. 
Pengukuran nyeri pada anak dapat dilakukan dengan autoanamnesis, pemeriksaan fisis, observasi tingkah laku, dan pengukuran fisiologis. ${ }^{15}$ Anammesis umumnya dapat dilakukan pada anak di atas 3 tahun dan sebaiknya dilakukan dengan melibatkan orangtua. Beberapa teknik yang dapat digunakan untuk menggambarkan nyeri adalah visual analog scale (VAS), numerical scale dan faces scale ${ }^{12,15-17}$ (Gambar 1). Visual analog scale dan numerical scale merupakan sebuah skala garis lurus berukuran $10 \mathrm{~cm}$, tetapi teknik VAS tidak menggunakan angka untuk menunjukkan intensitas nyeri. Kedua teknik ini dapat digunakan untuk anak berusia lebih dari 7 tahun. Faces scale dapat digunakan untuk menilai nyeri pada anak berusia 3-7 tahun yang dapat berkomunikasi dan sudah mengerti konsep 'lebih dan kurang'.

Observasi tingkah laku dapat digunakan pada bayi atau anak yang belum dapat bicara. Teknik pengukuran yang dapat digunakan adalah FLACC scale dan Riley infant pain scale (lihat Tabel 1 dan 2). ${ }^{13}$ Skala FLACC

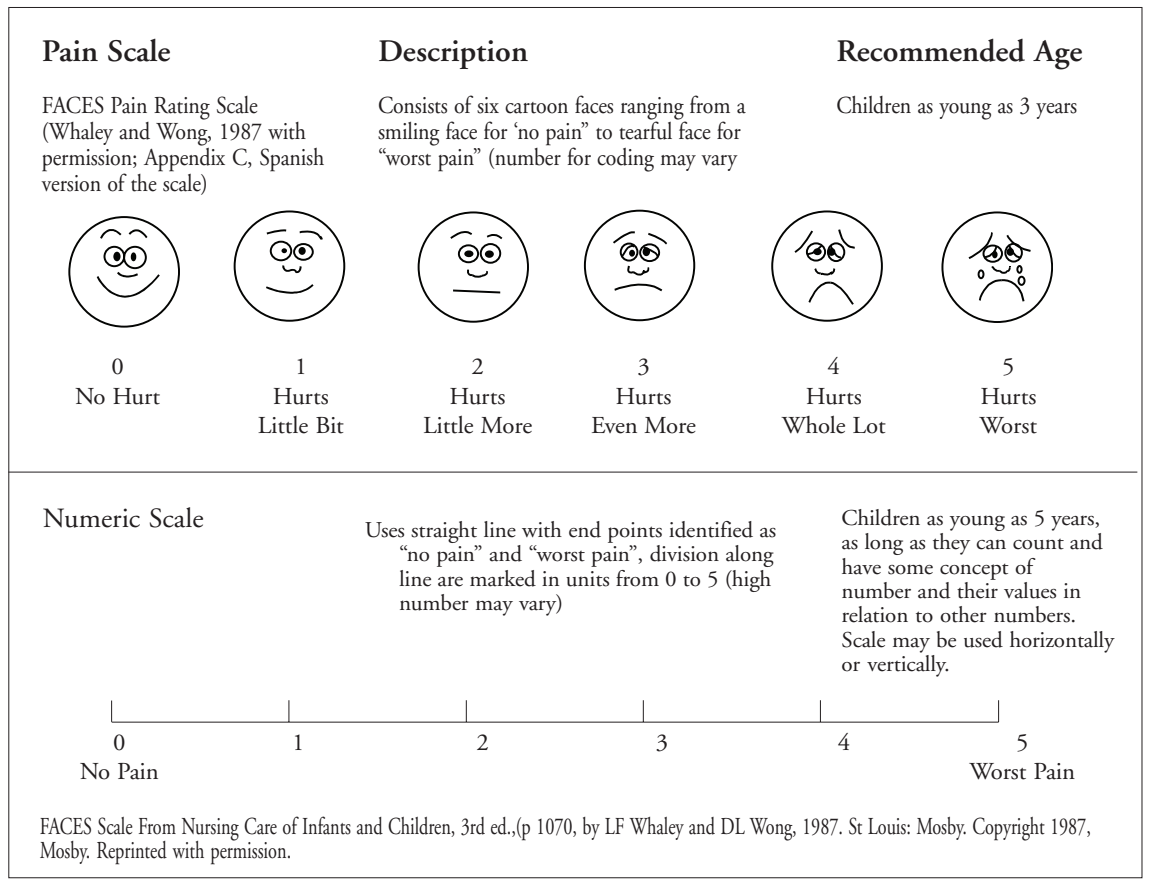

Gambar 1. Beberapa skala pengukuran nyeri

Dikutip dari: Hockenberry-Eaton M, Barrera P, Brown M, Bottomley SJ, O’Neill JB. ${ }^{15}$

Tabel 1. FLACC Scale

\begin{tabular}{|c|c|c|c|}
\hline \multirow[b]{2}{*}{$\underline{\text { Kategori }}$} & \multicolumn{3}{|c|}{ Skor } \\
\hline & 0 & 1 & 2 \\
\hline Face (Wajah) & $\begin{array}{l}\text { tidak ada ekspresi } \\
\text { khusus, senyum }\end{array}$ & $\begin{array}{l}\text { menyeringai, mengerutkan dahi } \\
\text { tampak tidak tertarik } \\
\text { (kadang kadang) }\end{array}$ & $\begin{array}{c}\text { dagu gemetar, gigik gemertak } \\
\text { (sering) }\end{array}$ \\
\hline Legs (Kaki) & normal, rileks & gelisah, tegang & menendang, kaki tertekuk \\
\hline Actifity (aktifitas) & $\begin{array}{l}\text { berbaring tenang, posisi } \\
\text { normal, gerakan mudah }\end{array}$ & $\begin{array}{l}\text { menggeliat, tidak bisa diam } \\
\text { tegang }\end{array}$ & kaku atau kejang \\
\hline Cry (Menangis) & tidak menangis & $\begin{array}{l}\text { merintih, merengek } \\
\text { kadang-kadang mengeluh }\end{array}$ & $\begin{array}{l}\text { terus menangis, berteriak } \\
\text { sering mengeluh }\end{array}$ \\
\hline Consolability & rileks & $\begin{array}{c}\text { dapat ditenangkan dengan } \\
\text { sentuhan, pelukan, bujukan, } \\
\text { dapat dialihkan }\end{array}$ & sulit dibujuk \\
\hline
\end{tabular}

Dikutip dengan modifikasi: Hockenberry-Eaton M, Barrera P, Brown M, Bottomley SJ, O’Neill JB. ${ }^{15}$ 
Sari Pediatri, Vol. 7, No. 3, Desember 2005

Tabel 2. Riley Infant Pain Scale

\begin{tabular}{|c|c|c|c|c|}
\hline Kategori & 0 & 1 & 2 & 3 \\
\hline Wajah & netral/senyum & $\begin{array}{l}\text { menyeringai } \\
\text { mengerutkan dahi }\end{array}$ & menggertakan gigi & terus menangis \\
\hline Gerakan tubuh & tenang, rileks & gelisah tidak tenang & agitasi sedang & $\begin{array}{l}\text { gerakan memukul } \\
\text { agitasi terus menerus } \\
\text { mengkakukan tubuh }\end{array}$ \\
\hline Tidur & tenang rileks & tidur gelisah & sering terbangun & $\begin{array}{l}\text { mudah terbangun } \\
\text { dengan sentuhan } \\
\text { tidak bisa tidur }\end{array}$ \\
\hline Verbal/vokal & tidak menangis & $\begin{array}{l}\text { menangis merintih } \\
\text { mengeluh }\end{array}$ & menangis kesakitan & $\begin{array}{l}\text { berteriak, } \\
\text { high pitched cry }\end{array}$ \\
\hline $\begin{array}{l}\text { Consolability } \\
\text { Respon terhadap } \\
\text { sentuhan }\end{array}$ & $\begin{array}{l}\text { netral } \\
\text { gerakan mudah }\end{array}$ & $\begin{array}{l}\text { mudah dibujuk } \\
\text { mengerinyit jika } \\
\text { disentuh atau bergerak }\end{array}$ & $\begin{array}{l}\text { tidak mudah dibujuk } \\
\text { menangis bila disentuh } \\
\text { atau bergerak }\end{array}$ & $\begin{array}{l}\text { tidak dapat dibujuk } \\
\text { berteriak, high pitched } \\
\text { cry jika } \\
\text { disentuh atau bergerak }\end{array}$ \\
\hline
\end{tabular}

Dikutip dengan modifikasi: Hockenberry-Eaton M, Barrera P, Brown M, Bottomley SJ, O’Neill JB. ${ }^{15}$

dapat digunakan pada anak berusia 2 bulan sampai 7 tahun, sedangkan riley infant pain scale dapat digunakan untuk menilai nyeri pada bayi.

Pengukuran respons fisiologis merupakan pengukuran tambahan yang mencakup flushing, berkeringat, peningkatan tekanan darah, takikardia, takipnea, penurunan saturasi oksigen, dan dilatasi pupil. ${ }^{15,18}$

\section{Penanganan Nyeri Kanker}

Tujuan utama tata laksana keganasan pada anak adalah menyembuhkan pasien dengan menitikberatkan pada terapi kuratif. ${ }^{8}$ Jika keganasan bertambah berat dan terapi kuratif tidak menunjukkan respon yang baik, maka terapi paliatif harus mulai dipertimbangkan. ${ }^{2}$ American Academy of Pediatrics (AAP) merekomendasikan pemberian terapi kuratif bersamaan dengan terapi paliatif untuk stadium lanjut dan terminal. ${ }^{18}$ Sampai saat ini sebagian besar anak dengan keganasan tidak mendapatkan penanganan nyeri yang adekuat, hal ini karena adanya perbedaan penilaian derajat nyeri antara pasien dan dokter, keengganan meresepkan opioid karena takut terjadi adiksi, toleransi dan efek samping. ${ }^{1,7,19}$

Penanganan nyeri dapat dilakukan dengan terapi farmakologis dan non farmakologis. ${ }^{20}$ Sekitar $80-90 \%$ pasien keganasan dengan keluhan nyeri dapat diatasi dengan pemberian analgesik, terutama morfin. ${ }^{21}$ Strategi penanganan nyeri secara farmakologis yang digunakan saat ini berpedoman pada pedoman yang dikeluarkan oleh $\mathrm{WHO}^{4}$, sebagai berikut.

- By the clock. Terapi harus diberikan dengan jadwal tertentu untuk mencegah awitan nyeri. ${ }^{7}$

- By the appropriate route. Terapi harus diberikan dengan cara yang mudah dan dapat diterima oleh pasien.

- By the child. Pemberian dosis terapi harus disesuaikan dengan kondisi pasien.

Analgesik harus diberikan berdasarkan derajat nyeri pasien. World Health Organization telah membuat rekomendasi terapi analgesik yang digambarkan seperti tangga $^{3-5}$ (Gambar 2).

\section{Terapi Farmakologis}

\section{- Analgesik non opioid}

Anti inflamasi non steroid (AINS) bekerja dengan cara menghambat enzim siklooksigenase, sehingga mengganggu konversi asam arakhidonat menjadi prostaglandin yang merupakan mediator nyeri. Obat ini umumnya bekerja di perifer, kecuali parasetamol yang bekerja di susunan saraf pusat dengan meng- 


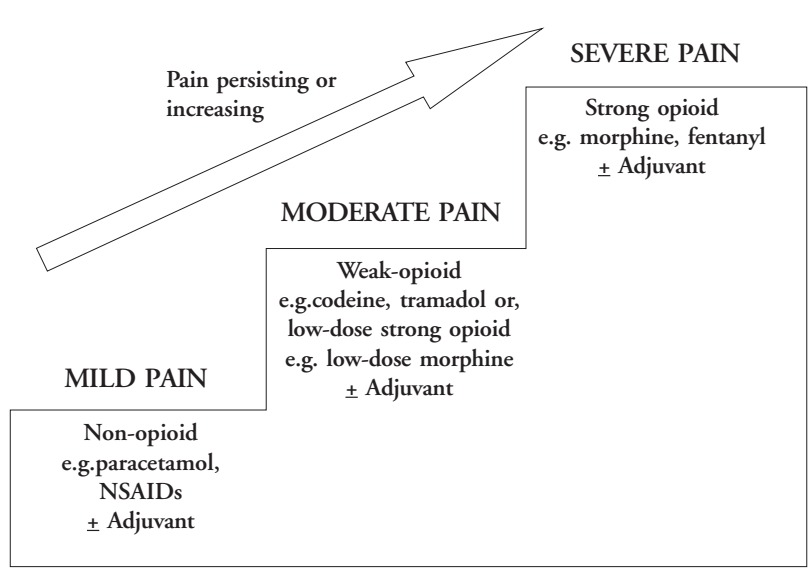

Gambar 2. WHO Analgesic Ladder

Dikutip dari: Ministry of Health Singapore. Clinical practice guidelines: cancer pain, 2003. ${ }^{5}$

hambat sintesis prostaglandin di hipotalamus. ${ }^{22}$ Berdasarkan rekomendasi WHO, AINS sebagai analgesik tunggal efektif untuk mengatasi nyeri kanker ringan. Untuk nyeri sedang dan berat, AINS dapat diberikan untuk meningkatkan efek analgesik opioid.

Anti inflamasi non steroid mempunyai ceiling effect, yaitu pemberian dosis yang lebih tinggi dari dosis maksimal, namun tidak menyebabkan bertambahnya efek analgesik. ${ }^{20}$ Penggunaan AINS jangka panjang memberikan banyak efek samping.

\section{- Analgesik opioid}

Opioid merupakan pilihan utama pada nyeri keganasan sedang berat. Terdapat 2 jenis opioid, yaitu opioid lemah seperti kodein dan tramadol; sedangkan opioid kuat yaitu morfin, metadon, fentanil, dan heroin. Opioid sedapat mungkin diberikan dalam bentuk oral, dan sebaiknya diberikan secara rutin agar tercapai kadar opioid plasma yang stabil. ${ }^{23}$

Opioid tidak memiliki standar dosis dan ceiling effect. Dosis yang diberikan sebaiknya dititrasi sesuai dengan rasa nyeri yang dialami pasien. Opioid sering menimbulkan efek samping, seperti sedasi, konstipasi, mual, muntah, dan depresi pernapasan. Pada anak, pemberian opioid sebaiknya diikuti dengan pemberian laksatif. Pada anak usia kurang dari 1 tahun, pemberian opioid harus dilakukan secara hati-hati karena dosis standar untuk anak sering menyebabkan depresi pernapasan. Pemberian opioid dapat menyebabkan ketergantungan, adiksi dan toleransi, namun adiksi jarang terjadi pada anak. ${ }^{16,23}$

\section{- Terapi ajuvan}

Obat ajuvan dapat dibedakan menjadi 2 bagian, yaitu obat yang bekerja sebagai ko-analgesik (meningkatkan kerja analgesik) dan obat yang mengurangi efek samping atau toksisitas analgesik. ${ }^{7,15}$ Obat ko-analgesik, mencakup anti depresan (seperti amitriptilin), anti konvulsan (seperti karbamazepin dan diazepam), dan kortikosteroid.

\section{Terapi Non Farmakologis}

Intervensi non farmakologis yang sesuai umur dapat digunakan untuk mengurangi rasa nyeri. Tindakan ini tidak dapat mengganti peran analgesik, melainkan meningkatkan efektivitas terapi farmakologis. Distraksi atau mengalihkan perhatian dapat dilakukan untuk mengurangi rasa nyeri yang disebabkan tindakan medis, seperti pemasangan infus atau pemberian sitostatik. Teknik lain yang dapat menenangkan anak adalah dengan memegang, memijat, mengelus, dan mengayun. ${ }^{24}$

\section{Daftar Pustaka}

1. Hartmann LC, Zahasky KM, Grendahl DC. Management of cancer pain: safe, adequate analgesia to improve quality of life. Postgraduate medicine 2000. Didapat dari: http://www.postgradmed.com/issues/2000/03_00/ hartmann.htm. Diakses tanggal 19 September 2004.

2. Masera G, Spinetta JJ, Jankovic M, Ablin AR, D'Angio GJ, Van Dongen-Melman J, dkk. Guidelines for assistance to terminally ill children with cancer: a report of SIOP Working Committee on Psychosocial Issues in Pediatric Oncology. Med Pediatr Oncol 1999;32:44-8.

3. Scottish Intercollegiate Guidelines Network. Control of pain in patients with cancer: a national clinical guideline. Didapat dari: http://www.sign.ac.uk. Diakses tanggal 11 September 2004.

4. World Health Organization. Cancer pain relief and palliative care in children 1998. Didapat dari: http:// www.indiacancer.org/profl cprc.html. Diakses tanggal 25 September 2004.

5. Ministry of Health Singapore. Clinical practice guide- 
lines: cancer pain, 2003. Didapat dari: http://www.gov.sg/ moh/pub/cpg/cpg.htm. Diakses tanggal 25 Septembar 2004.

6. American Medical Association. Pain management: pathophysiology of pain and pain assessment. Didapat dari: http://www.ama-meonline.com/ pain_mgmt/module01/index.htm. Diakses tanggal 19 September 2004.

7. Ripamonti C, Bruera E. Pain and symptom management in palliative care. Didapat dari: http://www.moffitt. usf.edu/pubs/ccj/v3n3/article2.html. Diakses tanggal 11 September 2004.

8. Wolfe J, Grier HE, Klar N, Levin SB, Ellenbogen JM, Salem-Schatz S, dkk. Symptoms and suffering at the end of life in children with cancer. $N$ Eng J Med 2000;342:326-33.

9. Kusumawardani S, Netty. Penatalaksanaan nyeri pada pasien kanker anak di bangsal hematology onkologi RSUD Dr Soetomo 1998. Dalam: Firmansyah A, Trihono PP, Oswari H, Nurhamzah W, Darmawan, penyunting. Buku abstrak Konika XI-Jakarta. Jakarta: IDAI Pusat; 1999. h. 210. [Abstrak]

10. Runtuwene T. Nyeri kanker. Dalam: Meliala KRTAL, Suryamiharja A, Purba JS, Sadeli HA, penyunting. Nyeri neuropatik: patofisiologi dan penatalaksanaan. Jakarta: Kelompok Studi Nyeri PERDOSSI; 2001. h. 121-8.

11. Kurnianda J. Etiologi dan patogenesis nyeri kanker. Berkala Neuro Sains 2003;4 Suppl 2:45-50.

12. Collins J, Shimoyama N, Bruera E, Takeda F, Kakizoe T, Sugimura T. Report of the $14^{\text {th }}$ international symposium of the Foundation for Promotion of Cancer Research: pain control, palliative medicine and psychooncology. Jpn J Clin Oncol 2001;31:459-68.

13. Meliala KRTAL. Patofisiologi nyeri. Dalam: Meliala KRTAL, Suryamiharja A, Purba JS, Sadeli HA, penyunting. Nyeri neuropatik: patofisiologi dan penatalaksanaan. Jakarta: Kelompok Studi Nyeri PERDOSSI; 2001. h. 1-22.

14. Lazuardi S. Nyeri pada anak. Dalam: Meliala KRTAL,
Suryamiharja A, Purba JS, Sadeli HA, penyunting. Nyeri neuropatik: patofisiologi dan penatalaksanaan. Jakarta: Kelompok Studi Nyeri PERDOSSI; 2001. h. 179-90.

15. Hockenberry-Eaton M, Barrera P, Brown M, Bottomley SJ, O'Neill JB. Pain management in children with cancer. Texas Cancer Council 1999. Didapat dari: http:// childcancerpain.org. Diakses tanggal 25 September 2004.

16. Goldman A. ABC of palliative care: special problems of children. BMJ 1998;316:49-52.

17. Hinnant DW. Psychological evaluation and testing. Dalam: Tollison CD, Satterthwaite JR, Tollison JW, penyunting. Handbook of pain management, edisi ke2. Maryland: Williams \& Wilkins; 1994. h. 18-35.

18. American Academy of Pediatrics. Palliative care for children: Committee on Bioethics and Committee on Hospital Care. Pediatrics 2000;106:351-7.

19. Zhang H, Wei-Ping G, Joransen DE, Cleeland C. People's Republic of China: status of cancer pain and palliative care. J Pain Symptom Manage 1996;12:1246.

20. McKenzie CA, Hobbs AE, Warrick LE. Pain management in cancer patient. US Pharmacist. Didapat dari: http://www.uspharmacist.com/oldformat.htm. Diakses tanggal 19 September 2004.

21. Davis MP. Cancer pain. Didapat dari: http://www. clevelandclinicmeded.com/diseasemanagement/hematology/ cancerpain.htm. Diakses tanggal 11 September 2004.

22. Wilmana PF. Analgesik-antipiretik: analgesik antiinflamasi non steroid dan obat pirai. Dalam: Ganiswarna SG, Setiabudy R, Suyatna FD, Purwantyastuti, Nafrialdi, penyunting. Farmakologi dan terapi, edisi ke-4. Jakarta : Bagian Farmakologi FKUI; 1995. h. 207-22.

23. American Pain Society. Principles analgesic use in the treatment of acute pain and cancer pain, Edisi ke-3. Skokie: American Pain Society; 1993. h. 1-43.

24. Anghelescu D, Oakes L. Working toward better cancer pain management for children. Cancer Practice 2002;10 Suppl 1:S52-7. 